Results StarShipTM was used to classify 250 PBMC (50 each of CD14 monocytes, CD19 B cells, CD4 helper T cells, CD8 $\mathrm{T}$ cells, and CD56 NK cells). Using dynamic spherical kmeans, 6 clusters were generated that closely corresponded to the known cell types (figure 1). For comparison, hierarchical clustering and one-off spherical k-means with $\mathrm{k}$ set to 5 were carried out. Hierarchical clustering had an ARI of 0.45 , oneoff spherical k-means had an ARI of 0.89 , and dynamic spherical k-means had an ARI of 0.86 .

Conclusions This method can effectively partition unknown cells from scRNA-Seq data sets into biologically relevant clusters without prior knowledge of the number of cell types present. The similarity between the performance of the StarShipTM algorithm and one-off k-means, which does incorporate this prior knowledge, highlights the value of this dynamic technique. A full analysis of the AMP LN data is forthcoming. Acknowledgments Research supported by the RILITE Foundation.

\section{BD-09 PRELIMINARY REPORT: RULE-BASED ALGORITHMS USING SYSTEMIC LUPUS INTERNATIONAL COLLABORATING CLINICS (SLICC) CLASSIFICATION CRITERIA TO IDENTIFY PATIENTS WITH SYSTEMIC LUPUS ERYTHEMATOSUS (SLE) FROM ELECTRONIC HEALTH RECORD (EHR) DATA}

${ }^{1,2}$ Anika S Ghosh, ${ }^{1,2}$ Theresa L Walunas, ${ }^{1,2}$ Kathryn L Jackson, ${ }^{1}$ Anh $\mathrm{H}$ Chung, ${ }^{1}$ Daniel L Erickson, ${ }^{1}$ Karen Mancera-Cuevas, ${ }^{1,2}$ Abel N Kho, ${ }^{1}$ Rosalind Ramsey-Goldman*. ${ }^{1}$ Northwestern University Feinberg School of Medicine, Chicago, IL, USA; ${ }^{2}$ Center for Health Information Partnerships, Chicago, IL, USA

\subsection{6/lupus-2018-Ism.33}

Background SLE is difficult to diagnose given diverse manifestations that occur over time and across care sites. Electronic health records (EHR) are now used in a majority of health care settings throughout the country, and present a rich source of information about patients which can be mined for earlier diagnosis identification, to improve quality of care, or enable clinical studies. To identify SLE patients in EHR data, we developed a rules-based algorithm based on the SLICC classification criteria and compared against a gold standard SLE patient registry data set.

Methods We identified 513 patients in the Chicago Lupus Database (CLD) fulfilling 4 or more of the ACR classification criteria for SLE who also had records in the Northwestern Medicine Electronic Data Warehouse (NMEDW). ICD-9/10 codes were used to identify clinical SLICC SLE classification criteria items. Laboratory results were identified using lab test names in combination with threshold numeric values in order to determine whether patients met the SLICC lab test classification criteria requirements.

Results As shown in table 1, of 513 patients with SLE in the CLD, we detected the following SLICC classification criteria, in the NMEDW: clinical- chronic cutaneous 97\%; acute cutaneous 98\%; renal 65\%; serositis 52\%; arthritis 34\%; neuro $29 \%$; ulcers $16 \%$; alopecia $1 \%$; and labs- dsDNA $89 \%$; hemolytic anemia $80 \%$; complement $74 \%$; leukopenia/lymphopenia 73\%; APL 64\%; ANA 52\%; thrombocytopenia 22\%; Coombs 17\%; Sm 0\%.

Of 513 patients with SLE in the CLD based on ACR criteria, 513 had at least 1 clinical criteria, 466 had at least 1 immunologic criteria, and 471 had 4 or more criteria. Using EHR data from the NMEDW, and rules for the SLICC classification criteria that were based on ICD9/10 codes and labs and required identification of at least one clinical and one immunological criteria, we categorized 450/513 (88\%) patients as having definite lupus.

\begin{tabular}{|c|c|c|c|}
\hline SLICC Criteria & $\begin{array}{l}\text { Identified in } \\
\text { CLD } \\
\text { (N) }\end{array}$ & $\begin{array}{l}\text { Identified in } \\
\text { NMEDW (N) }\end{array}$ & $\begin{array}{l}\text { Identified in CLD and } \\
\text { NMEDW (\%) }\end{array}$ \\
\hline \multicolumn{4}{|l|}{ Clinical } \\
\hline acute cutaneous & 435 & 425 & $98 \%$ \\
\hline Chronic cutaneous & 146 & 141 & $97 \%$ \\
\hline Renal & 182 & 118 & $65 \%$ \\
\hline Serositis & 221 & 115 & $52 \%$ \\
\hline Arthritis & 472 & 161 & $34 \%$ \\
\hline Neurological & 205 & 59 & $29 \%$ \\
\hline Oral ulcers & 281 & 46 & $16 \%$ \\
\hline Alopecia & 96 & 1 & $1 \%$ \\
\hline \multicolumn{4}{|l|}{ LABORATORY } \\
\hline Anti-dsDNA Ab & 348 & 310 & $89 \%$ \\
\hline Hemolytic Anemia & 5 & 4 & $80 \%$ \\
\hline Complement & 500 & 368 & $74 \%$ \\
\hline $\begin{array}{l}\text { Leukopenia/ } \\
\text { Lymphopenia }\end{array}$ & 508 & 369 & $73 \%$ \\
\hline $\begin{array}{l}\text { Anti-phospholipid } \\
\text { antibody }\end{array}$ & 131 & 84 & $64 \%$ \\
\hline $\begin{array}{l}\text { Anti-nuclear } \\
\text { antibody }\end{array}$ & 433 & 226 & $52 \%$ \\
\hline Thrombocytopenia & 454 & 98 & $22 \%$ \\
\hline Coombs & 12 & 2 & $17 \%$ \\
\hline Anti-Smith antibody & 109 & 0 & $0 \%$ \\
\hline
\end{tabular}

Conclusions Query of patient EHR data with ICD-9/10 codes and lab tests for specific SLICC classification criteria items requires refinement to improve identification of some criteria. Using the SLICC classification rule for definite SLE, we were able to identify $88 \%$ of those with definite SLE by the ACR criteria, using ICD9/ 10 codes and labs. Text searching of notes (by simple string matching or natural language processing) may improve identification of individual SLICC criteria (e.g. renal biopsy) and may be critical for mining physicians' notes for criteria that are not well documented with diagnosis codes or lab results.

Acknowledgements Funding-NIH/NIAMS R21AR074081.

\section{BD-10 THE DISTRIBUTION OF INSURANCE IN A POPULATION- BASED COHORT OF SLE: GEORGIANS ORGANIZED AGAINST LUPUS COHORT}

S Sam Lim*, Gaobin Bao, Cristina Drenkard. Emory University, Department of Medicine, Division of Rheumatology, Atlanta, Georgia USA

\subsection{6/lupus-2018-Ism.34}

Background Having health insurance coverage is important for people with chronic conditions. Those with systemic lupus erythematosus (SLE) are particularly vulnerable given the disproportionate impact on young minorities and women. This is the first description of health insurance changes over time overall and by sociodemographic groups on a population level. 